\title{
Scenario forecasting of the economic effects of agricultural modernization in digital economy
}

\author{
Elmira Amirova ${ }^{1, *}$, Elena Gubanova ${ }^{2}$, Vladimir Krivoshlykov ${ }^{3}$ and Nikolay Zhakhov ${ }^{4}$ \\ ${ }^{1}$ Kazan State Agrarian University, Kazan, 420015, Russia \\ ${ }^{2}$ Kaluga branch of Financial University under the Law of the Russian Federation, Kaluga, 248016, Russia \\ ${ }^{3}$ Kursk State University, Kursk, 305000, Russia \\ ${ }^{4}$ Southwest State University, Kursk, 305021, Russia
}

\begin{abstract}
This paper studies the international models of digital development of the agricultural sector of economy and its structural elements used in the emerging models of innovative development of the Russian Federation. Various scenarios of forecasting of the economic effects of agricultural production development are presented. It allowed drawing a conclusion about the low level of compliance of digital economy with the necessary science-intensive indicator of gross domestic product, which requires radical government intervention and the reorganization of economy as a whole. It is possible to state that, first of all, it is necessary to create an appropriate theoretical knowledge base, using which it would be possible to carry out the process of training the necessary skills and competencies in the development of digital economy in Russian universities. International exchange of students and post graduate students is also extremely productive in terms of the development of new technologies. This is illustrated by the US agrarian statistical analysis in the field of modernization effects. Thus, the problem of scenario forecasting of the economic effects of agricultural modernization in digital economy is quite relevant and requires additional scientific research in this direction.
\end{abstract}

\section{Introduction}

The problem of scenario forecasting of the economic effects of agricultural modernization affects both the Russian government and entrepreneurs who are ready to invest in the modernization of the agro-industrial complex in the era of digital economy. In Russian agricultural practice, one of the most relevant issues in modern economic conditions is the safety of raw materials during gathering and further transportation.

In order to solve these issues, it is necessary to equip the vehicle fleet with special GPS-modules, which, in addition to the ability to monitor the current location of a single transport unit, can reduce fuel consumption by up to $20 \%$ due to competent logistics in the form of correct route planning. Moreover, the installation of appropriate sensors on transport allows tracking the weight of transferred raw materials, thus leveling the possibility of personnel fraud. It was proven that the degrees of modernization of agriculture in the digital age differ significantly from the goals and timing of their implementation. The effect of the modernization will be reflected in the upcoming decades.

The analysis of the modernization potential of Russian agricultural enterprises shows that they are largely limited due to the advanced imported technologies they use. The volume of imported technologies sometimes exceeds $50 \%$.
The need of companies for advanced production technologies is partially satisfied by the acquisition of technologies in Russia. Nearly a half of all applied solutions are imported and organizations develop independently less than $10 \%[13,15]$.

As it turned out, for the period 2012-2019 the number of advanced production technologies increased by $29 \%$ and in 2019 amounted to almost 230 thousand units in absolute terms. At the same time, the share of the financial and economic centers of the country and regions with a diversified economy is more than $40 \%$ of the production solutions developed in the country.

The innovative strategies focused on the independent development of new solutions are poorly distributed in Russia. Less than $20 \%$ of companies satisfy the need for advanced production technologies using their own resources. The majority of companies purchase technologies in Russia or abroad.

Nowadays digital technologies play a key role in the innovative development of the country. At the same time, one of the main problems affecting the very terminology of digital economy is the lack of a clear and universal definition of this category. The term "digital economy" appeared for the first time in Tapscott, 1996: The Digital Economy: Promise and Peril in the Age of Networked Intelligence.

\footnotetext{
Corresponding author: elmira_amirova@mail.ru
} 
Moreover, the author does not directly define the digital economy, but uses the concept of the "Age of Networked Intelligence", the essence of which is "not only in network technologies ... but in the interaction of people through network technologies", which "unite intelligence, knowledge and creativity to make a breakthrough in the creation of social capital and wellbeing".

Within the framework of the state program "Digital Economy of the Russian Federation", this category is defined as "economic activity, the key production factor in which is data in digital form, contributing to the formation of an information society, taking into account the needs of citizens in high-quality and reliable information, the development of the information infrastructure of the Russian Federation, the creation and application of Russian information and telecommunication technologies, as well as the formation of a new technological basis for the social and economic sphere "[1].

A more specific definition of digital economy is given by the Bureau of Economic Analysis of the US Department of Commerce. It considers it in terms of the means of the Internet and related information and communication technologies. During the development of this definition, the Bureau relied on analytical experience and available materials and statistics on digital economy. The Bureau took the ICT sector as a starting point in its work on the definition of digital economy.

Revealing the problems of the given topic, we would like to draw attention to the Russian agrarian complex from a number of points of view. Firstly, it is necessary to realize that the modern economic effects in the modernization of the Russian agrarian complex can not exist without the effects of the introduction of digital economy.

Secondly, in the next 20-30 years, no easing in the problems of modernization is planned. Only further expansion of international cooperation is planned, since it is the guarantor of the forward movement from smallscale agricultural production to the optimal scale of activity $[6,9]$.

Thirdly, the economic effects of the modernization of agriculture and agro-industrial complex in Russia can be both positive and negative. The negative ones include the increase in unemployment as a result of the widespread introduction of robotic technology, which works faster, better and more qualitatively. At the same time, the government will be forced to transfer a significant part of the labor force from the agro-industrial complex to the related areas of service provision, production and sale of goods [1].

\section{Methods}

This research was carried out on the basis of the analysis of a large number of literary sources, which allowed the authors to study modern achievements in the field of digitalization of agriculture in order to build scenario forecasts of the economic effects of agricultural modernization in digital economy. The achievement of the stated purpose in this work is provided by the use of a critical analysis of literary sources, general scientific methods of the system approach, analogy and design, abstract-logical and statistical-economic methods.

\section{Results and Discussion}

In the emerging model of scientific and innovative development of Russia, the elements of various foreign models are used, which allows taking into account the specifics of the existing relations in the market of scientific products and the existing infrastructure of scientific and innovative services.

In the countries that have chosen the innovative path of development as a priority, the threshold value of the science intensity of the gross domestic product in terms of economic, scientific and technical security is $2 \%$. The decrease in the science intensity of the gross domestic product to the level of $0.3-1 \%$ for more than 5-7 years leads to an irreversible degradation of the innovative potential of a country. The states of Southeast Asia and the Scandinavian countries (Finland, Sweden) have become the regions of the accelerated expansion of the scientific and technical sphere in recent years. Newly industrialized countries (Hong Kong, Singapore, Taiwan, South Korea) have increased the science intensity of GDP by 1.5-2 times and are approaching the indicators of European countries and the United States.

According to American digital business practitioners, farmers who own cultivated areas and slaughter houses are the first initiators of agricultural modernization. However, we can not unambiguously correlate these effects with the problems of the rapidly growing agricultural complex of the present time, since the era of digital technologies sets new goals and objectives for farmers [4]. The most challenging goals in 2020 were related to obtaining short-term credit-monetary subsidies from the largest banking institutions.

In Russia, these are Rosselkhoz Bank and Rosbank. Rosselkhoz Bank has the priority in terms of the use of modernized technologies for raising capital and rebuilding existing agricultural complexes. Nowadays there are more than 300 of them throughout Russia, while in the United States their number exceeded 1000 fifteen years ago. Thus, the following scenario forecasts of the economic effects of agricultural modernization in digital economy are typical for the modern Russian economy [2].

The $1^{\text {st }}$ scenario is as follows. The digitalization of agriculture in the Russian Federation will create the preconditions for the increase in production capacity reducing the share of rental payments in the cost of products. According to experts, this approach can increase the dependence of market on raw materials, strengthen the growing role of monetizing the sector and leveling bank capital in favor of functioning of agricultural industries.

The economic effect of it in the United States reduced the production risks by more than $20 \%$ in half a year. In France it reduced by about $35-47 \%$, depending on the region of implementation of projects for forecasting the economic effects of agricultural modernization in digital economy and these effects will continue until 2030. 
The $2^{\text {nd }}$ scenario is following. It is considered as the most acceptable for countries with arid climates and dependent economies of raw materials. Russia does not belong to this list of countries, but its financial capabilities in a number of regions do not allow taking effective measures to modernize the agricultural sector. In any case, the result of the introduction of certain modernization effects is obvious: the rapid increase in the production of grain crops by agricultural producers of various organizational and legal forms - LLC, OJSC and CJSC in the Russian Federation [5, 19].

The $3^{\text {rd }}$ scenario is mainly controversial, since for its implementation it is extremely important to mobilize the practical experience of agrarian Soviet Russia in relation to the management of industries that provide the country with meat, milk and vegetable oils. The fact is that it is these industries that are most significant in the manifestation of the economic effect of modernization until 2050. In other words, we propose to use planning mechanisms similar to five-year plans, since it is precisely such methods in the era of digitalization that are designed to protect the market from an overabundance of working and obsolete production assets [3, 17, 18].

The concept of Russian socio-economic development presupposes: the return of the country to the number of world technological leaders, a fourfold increase in labor productivity in the main sectors of the Russian economy, the increase in the share of the middle class to $60-70 \%$ of the population, decrease in mortality by 1.5 times and increase in average life expectancy to 75 years old. The concept determines the priorities of state policy such as the investment in human capital, the rise of education, science, health care, development of a national innovation system, modernization of economy and development of its new competitive sectors in high-tech spheres of the knowledge economy, reconstruction and expansion of production, social and financial infrastructure.

Taking into account the planned parameters of the concept, we will carry out a scenario forecast for the agricultural sector.

The presented scenarios provide the significant decrease in imports of food products and, accordingly, the increase in the food security of a country and retail turnover of food products, the increase in their exports.

The forecasted inflation will reduce the real incomes of the population in all the proposed scenarios [12]. The innovative scenario provides the decrease in the energy and electrical intensity of agricultural production, the significant increase in labor productivity in the industry. Further development and recovery of agriculture should be associated with the development of advanced technologies for the production of agricultural products, the use of modern productive equipment, the development of processing industries, the improvement of the use of land and other resources, the elimination of the disparity in prices for industrial and agricultural goods, the implementation of a set of state measures to support villages, the improvement of industrial and social infrastructure and on-farm relations, the improvement of service, the management of this area of production based on the application of modern scientific achievements $[14$, 21].
The fundamental feature of such a management system is an innovative approach to its organization and functioning $[4,7,20]$.

Forecasting the future, it is necessary to take into account all the factors affecting the change in demand for agricultural products. Then it is necessary to determine the degree of their influence on demand and make a forecast based on some method. The most common methods to determine a prospective need are normative, extrapolation, and expert judgment.

In order to satisfy the welfare of the population and provide Russians with domestic food products, taking into account the climatic and other characteristics of the country, Russian agricultural companies need to produce 120 million tons of grain, 4.0 million tons of sunflower seeds, 41.6 million tons of sugar beet and 32 million tons of vegetables annually. Domestic producers must annually supply 19-28 million tons of livestock and poultry in live weight, 55-67 million tons of milk and 4952 billion pieces of eggs.

The processing enterprises of the agro-industrial complex of the country need to produce 4-4.5 million tons of meat, including by-products of the first category, 4 million tons of granulated sugar from sugar beet, 1.2 million tons of vegetable oil, about 1 million tons of margarine and about 450 thousand tons of fish products. The priority goals of agricultural production in the framework of strategic management are the following $[8$, 10]:

- The intensification of the position of the industry, including the diversification of production and development of new markets;

- The improvement of the general financial and economic situation, which is achieved not only by the increase in production volumes, but also by a mode of economy, manipulation of its assets and regulation of financial settlements and a number of other actions;

- gaining a high business reputation, for which it is necessary to carry out an impeccable internal organizational policy, putting forward the timely fulfillment of concluded contracts, honesty in calculations and high level of quality of goods and services as unconditional priorities;

- The provision of high reliability in production and economic activities creating capacity and resource reserves, insuring reserve funds and a developed system of risk.

Thus, we received relatively well considered decisions regarding scenario forecasting of the economic effects of agricultural modernization in digital economy. The problems of the conceptual model to overcome the transition period are no less important. Taking into account the point of view of agricultural experts [6], the agro-industrial complex in Russia is very archaic and does not provide quick synchronization with industry, transport and communications.

The main obstacle to the implementation of long-term measures to improve the efficiency of agricultural production is the lack of practical flexibility between employers, government and banks. A negative point in this case is considered to be an insufficient level of computer equipment in agricultural production, a low 
level of professional suitability of more than $60 \%$ of workers in related industries, which are caused by the problems of economy.

\section{Conclusion}

As a result of our research we draw the following conclusions:

1. Scenario forecasting of the economic effects of agricultural modernization in digital economy is impossible without a high level of qualifications of personnel and the professionalism of local labor resources.

2. The level of economic development of the country as a whole is quite important.

3. The indicator of international mutual influence is also obvious according to the increase or decrease in trade, the search for buyers of agricultural products and the expansion of sales markets.

All these effects are stereotypes [6]. That is, they are possible only if the state and commercial banks of Russia fully subordinate the agricultural sector by 2025, since the peak of digitalization at the initial stage is scheduled precisely by 2025 .

Thus, theory should not disagree with practice and contradict it in the era of high digital technologies. First of all, it is necessary to plan more $r$ reasonable investment activities in the agricultural sector as a whole. Every year the state will spend at least three billion euros on modernization needs in order to approach the level of France and Spain by 2030.

The first stage of modernization is associated with the concept of the revision of the legislative acts of the Russian Federation, which will improve the efficiency of economic management and create more jobs in agriculture. Today we are talking about nearly 450 thousand people. By 2030, this number will drop to 230 thousand, while the efficiency from the introduction of digital economic system will be at least $67 \%$.

It can be stated that these numbers are optimistic, since the southern regions of Russia will be the first to be equipped with high-tech industries. It is also difficult to estimate the growth rate of industrial production due to the policy of economic effects of agricultural modernization in digital economy.

Concluding the aspects within the framework of the problem, we had to mobilize not only Russian data, but also information from international sources. They can be considered important, since without the use of advanced experience, there is no need to talk about the positive effect of the measures taken today in the field of environmental protection and a decrease in the profitability indicator.

Special sensors and monitoring software are designed to optimize the conditions and methods for the storage of agricultural products. Thus, the algorithms set by means of special software in real time can monitor the state of storage conditions of products, such as carbon dioxide content, temperature and humidity level in the production of agricultural products.
Smart greenhouses and smart farms can also be introduced into agricultural production practices and generate significant savings from more efficient use of water, fertilizers and chemicals in such greenhouses and farms [11]. In addition, these technologies will optimize the number of personnel involved in the cultivation of crops, as well as minimize losses associated with human factor [16].

Thus, we made the attempt to reveal the issue using different opinions and points of view, both from the standpoint of the experience of developed countries and the Russian concept of the implementation of high technologies.

\section{References}

1. A.U. Mentsiev, A. Isaev, Kh. Supaeva, S. Yunaeva, U. Khatuev, Advancement of mechanical automation in the agriculture sector and overview of IoT, APITECH-2019 Journal of Physics: Conference Series, 1399 (2019)

2. A.U. Mentsiev, Z. Gerikhanov, A. Isaev, Automation and IoT for controlling and analysing the growth of crops in agriculture, APITECH-2019 Journal of Physics: Conference Series, 1399 (2019)

3. E.F. Amirova, O.V. Kirillova, M.G. Kuznetsov, Sh.M. Gazetdinov, Internet of things as a digital tool for the development of agricultural economy, BIO Web of Conferences, 00050 (2020)

4. D.Kh. Krasnoselskaya, D.R. Khamzina, S.M. Goloviznin et al., Determination of capital accumulation in region using benchmarking tool, Espacios, 40(35) (2019)

5. D.V. Bunkovsky, Entrepreneurial risk management tools, Manag. Issues, 1(37), 65-76 (2019)

6. D.V. Bunkovsky, Methods for minimizing enterprise risks, Manag. Issues, 5(35), 125-129 (2018)

7. E.Yu. Ermakova, Yu.F. Korotkov, M.G. Kuznetsov, N.A. Nikolaev, Cleaning contaminated water by gravity flotation, Chem. and Petrol. Engineer., 46(12), 40-44 (May 2010)

8. R.V. Fattakhov, M.M. Nizamutdinov, V.V. Oreshnikov, Analysing and modelling of trends in the development of the territorial settlement system in Russia, Economy of Region, 15(2), 436-450 (2019)

9. T. Khudyakova, A. Shmidt, S. Shmidt, Implementation of controlling technologies as a method to increase sustainability of the enterprise activities, Entrepreneurship and Sustainability Issues, 7(2), 1185-1196 (2019)

10. T. Khudyakova, A. Shmidt, S. Shmidt, Sustainable development of smart cities in the context of the implementation of the tire recycling program, Entrepreneurship and Sustainability Issues, 8(2), 698-715 (2020)

11. O.V. Kirillova, E.F. Amirova, M.G. Kuznetsov, G.A. Valeeva, G.P. Zakharova, Innovative directions of agricultural development aimed at ensuring food 
security in Russia, BIO Web of Conferences, 00068 (2020)

12. D.K. Krasnoselskaya, D.R. Khamzina, S.M. Goloviznin, O.V. Nogovitsina, A.V. Sarapulova, E.S. Arishina, Determination of capital accumulation in region using benchmarking tool, Espacios, 40(35) (2019)

13. M. Zharova, S. Shirokova, O. Rostova, Management of pilot IT projects in the preparation of energy resources, E3S Web of Conf., 110, 02033 (2019)

14. N.F. Kashapov, M.M. Nafikov, M.X. Gazetdinov, M.M. Nafikova, A.R. Nigmatzyanov, Innovative production technology ethanol from sweet sorghum, IOP Conf. Ser. Mater. Sci. and Engineer., 134, 012012 (2016)

15. N.V. Zhakhov, V.S. Krivoshlykov, N.A. Slavova et al., State Influence on the Development of Digital Economy of Rational Nature Use in Agricultural Sector of the Region's Economy, in: Proc. of XVIII Int. Sci. and Pract. Conf. Modern Trends in Agricultural Production in the World Economy, pp. 182-189 (2020)

16. S. Novikov, E. Amirova, E. Kosykh, M. Chudinovskikh, O. Nikolaevskaya, Strategic planning and management of high-tech developments and innovative technical solutions, Research in World Economy, 10(3), 309-314 (2019)
17. O. Rostova, S. Shirokova, N. Sokolitsyna, Management of project for automation of investment control at industrial enterprise, IOP Conf. Ser. Mater. Sci. and Engineer., 497(1), 012017 (2019)

18. A.P. Garnov, N.A. Prodanova, E.V. Malakhova, N.P. Tishkina, H. Saadoon, Al.R. Chatheer, E.F. Amirova, The Eurasian economic union in the context of digital transformation: Main directions in the development of industrial cooperation, Webology, 17(1), 333-340 (2020)

19. I. Sokolova, O. Leskina, O. Orlovtseva, E. Gubanova, T. Kanikhin, Application of artificial intelligence capabilities for practical needs of participants in economic processes, in: Proc. of the 33th Int. Busin. Inform. Manag. Associat. Conf., IBIMA 2019: Education Excellence and Innovation Management through Vision 2020, pp. 8592-8602 (2019)

20. V. Timiryanova, K. Grishin, D. Krasnoselskaya, Spatial Patterns of Production-DistributionConsumption Cycle: The Specifics of Developing Russia, Economies, 8(4), 87 (2020). DOI: https://doi.org/10.3390/economies8040087

21. K. Yusupov, K. Grishin, V. Timiryanova, D. Krasnoselskaya, Spatial patterns of profitable firms' location: empirical evidence from Russia, Amazonia Investiga, 8(24), 452-463 (2019) 